\title{
AUTOMATIC AND LOW COST SALINE LEVEL MONITORING SYSTEM USING WIRELESS BLUETOOTH MODULE AND CC2500 TRANSRECEIVER
}

\author{
Mansi G. Chidgopkar ${ }^{1}$; Aruna P. Phatale ${ }^{2}$ \\ ${ }^{\text {I} M . E . ~ E l e c t r o n i c s, ~ J a w a h a r l a l ~ N e h r u ~ E n g i n e e r i n g ~ C o l l e g e, ~ M a h a r a s h t r a, ~ I n d i a ~}$ \\ (mgc131290@gmail.com) \\ ${ }^{2}$ M.E. Electronics, Jawaharlal Nehru Engineering College, Maharashtra, India \\ (arunaphatale@yahoo.com)
}

\begin{abstract}
bstract
Traditional methods used for health care are becoming obsolete due to increase in population. Current health care system requires manual care takers and their heavy duties which is very time consuming job. Innovative health monitoring systems are required with less human intervention which will be available at low cost in rural as well as urban areas. Engineering technologies are getting coupled with medical field to solve this problem. Sophisticatedhealth monitoring systems are getting developed with the help of electronic components such as sensors, PLC,microcontrollers etc. with easy interfacing.This paper mainly focuses on providing advanced saline level monitoring system. The idea is to provide cost effective, reliable and automatic saline flow monitoring system which can be easily implemented in any hospital and can be easy for doctors as well as nurses to monitor the saline flow from a distance. The proposed system eliminates continuous on sight monitoring of patient by nurses or doctors. Due to the use of microcontroller ATMEGA 328, wireless module CC2500, Bluetooth module and IR sensors, the system can be made available at very low cost. Thesame circuit can be reused for another saline bottle giving only one time investment.
\end{abstract}

Keywords: Microcontroller ATMEGA 328, Wireless module CC2500, Bluetooth module, saline bottle, IR sensor

\section{INTRODUCTION}

Due to the advancement in technology, the progress in medical field is rapid. A reason behind this is nothing but the combination of medical and engineering disciplines. When the Normal Saline (NS) is to be placed intravenously then it is called as sterile. Normal saline is generally referred as sterile solution of sodium chloride (Nacl) in water. Generally, in hospitals saline level is monitored by nurses and patients relatives. There is always a need to check the saline level after certain time. The existing system for saline level monitoring is very time consuming and inconvenient for nurses. The main objective of proposed system is to provide reliable, convenient, effortless and cost effective system for saline level monitoring. As the saline goes below the critical level, it is necessary to change the saline bottle. An automatic saline level monitoring system consists of IR sensors which are used to determine the status of liquid in the bottle whether it is normal or warning status. Bluetooth module and CC2500 wireless module act as transreciever, due to which the notification can be sent to the nurse on her mobile as well as computer. The speaker starts ringing when the liquid goes below the critical level and automatically nurse will get the notification of warning. Programming is done in microcontroller ATMEGA 328 which is best suitable for making the system cost effective.

\section{SYSTEM ANALYSIS AND DESIGN}

The transmitter part contains ATMEGA328, CC2500 wireless module transmitter, Bluetooth module, buzzer, IR sensor, green and red led and battery. The receiver part contains CC2500 wireless module receiver, computer or laptop and mobile (smart phone). The transmitter and receiver block diagrams are as shown in figures 1 and 2 .

\subsection{Ir Sensor}

IR sensor is used to detect the droplet coming from saline bottle. In this project, IR sensor transreciever is used. When the sensor transmitter detects the droplet then it transmits the signal to the receiver so that the receiver can receive the droplet and sends it to the comparator.

\subsection{Comparator}

The LM358 dual comparator is used. The comparator is used to modify the weak signals coming from the IR transreciever. It is used to compare the signal with its threshold value and then pass the appropriate signal to the microcontroller ATMEGA 328.

\subsection{Atmega 328}

28 pin controller. Oscillator circuit and reset circuit are given as input to the microcontroller. In this project, two serial communication It is the modules are used hence ATMEGA 328 microcontroller is best 


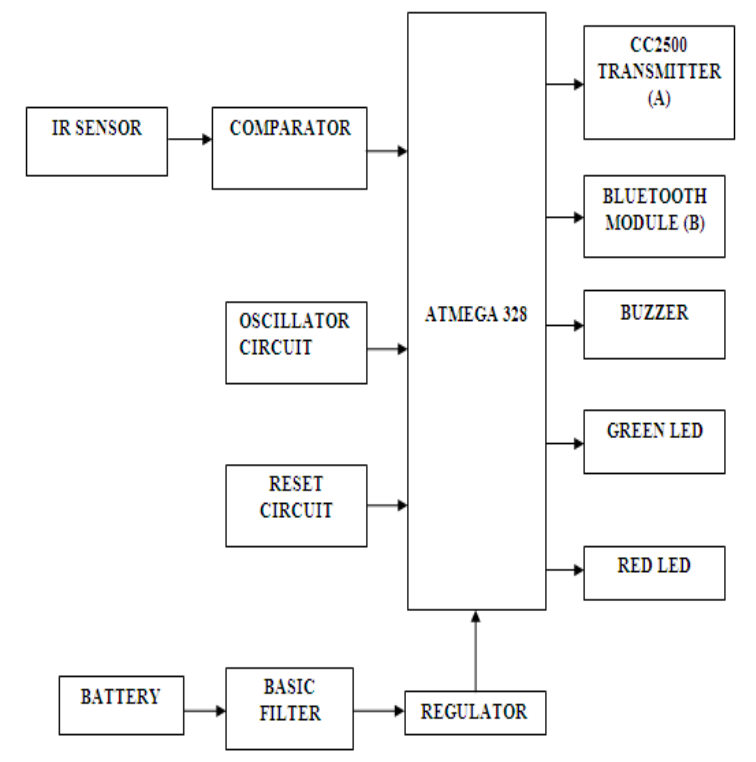

Fig-1: Block diagram of Transmitter

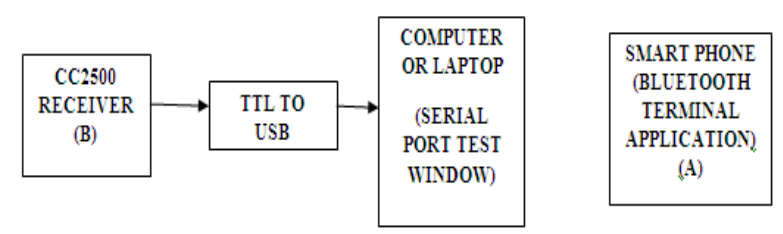

Fig-2: Block diagram of Receiver

suitable here. It is having flash memory of $32 \mathrm{Kbytes}$, EEPROM data memory of 1 Kbytes and SRAM data memory of 2 Kbytes. It has $23 \mathrm{I} / \mathrm{O}$ pins and two 8 bit, one 16 bit timers. It has 10 bit six channel A/D converter. There are six PWM channels. The processing speed of external oscillator is up to $20 \mathrm{MHz}$.

\subsection{Power Supply Unit}

The supply unit consists of battery, basic filter and regulator IC 7805 which is used to provide supply voltage of $5 \mathrm{v}$. There is a provision of using transformer as well as adaptor of 12 volt and 1 ampere current. If transformer is used then bridge rectifier and 1000 microfarad capacitor is provided.

\subsection{Cc2500 Wireless Module}

CC2500 wireless module acts as transreciever. Transmitter is used to transmit the data via microcontroller to the receiver. Receiver is connected to computer or laptop. TTL to USB converter is used to obtain information on computer or laptop so that nurse as well as doctor can recognize the saline level with the help of serial port test window which is displayed on computer or laptop. The Bluetooth module is used to send the data wirelessly on nurse's smart phone and the results are displayed with the help of Bluetooth terminal application. Due to the use of wireless modules, it is easy for nurses as well as doctors to check the saline level without going at patient's bed.

\subsection{Buzzer and Leds}

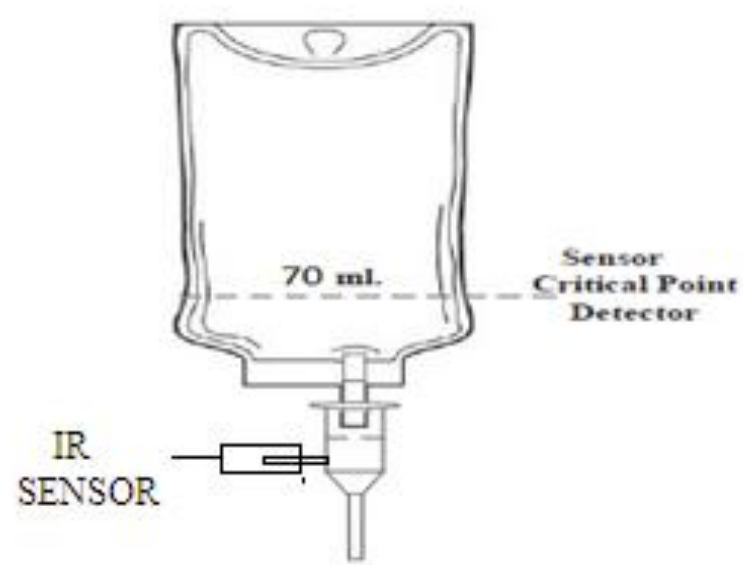

Fig-3: Droplets detection assembly

In the programming, the critical level is set at $70 \mathrm{ml}$. Generally, saline bottle contains $500 \mathrm{ml}$ solution. When the saline solution is above $70 \mathrm{ml}$ then green led will blink and when the saline solution falls below $70 \mathrm{ml}$ or the critical level then red led starts blinking and buzzer will start ringing so that it will be easy for nurses or patient's relatives to understand the exact position of remaining saline solution in the bottle.

\section{EXPECTED RESULTS}

The programming is based on arduino platform which is done using $\mathrm{C}$ compiler. The results are obtained on Smartphone with the help of Bluetooth terminal software and are obtained on computer or laptop using serial port test software. The results contain number of droplets coming from saline bottle, the solution given to patient in $\mathrm{ml}$, the droplet rate and remaining solution in bottle.

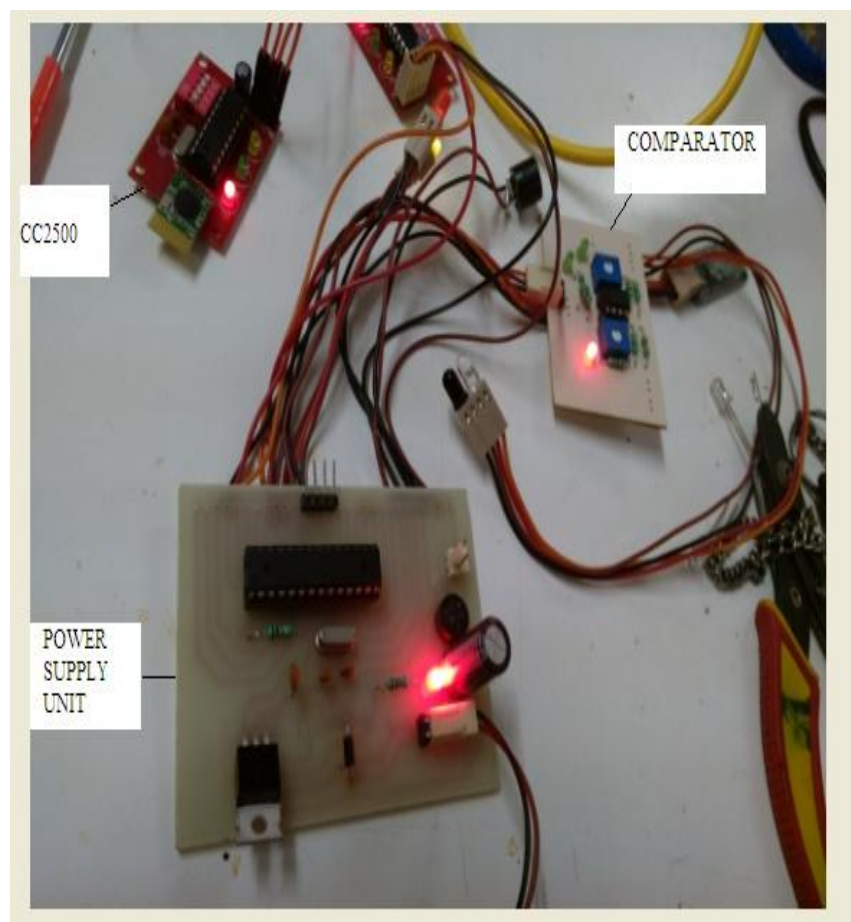

Fig-4: System hardware 


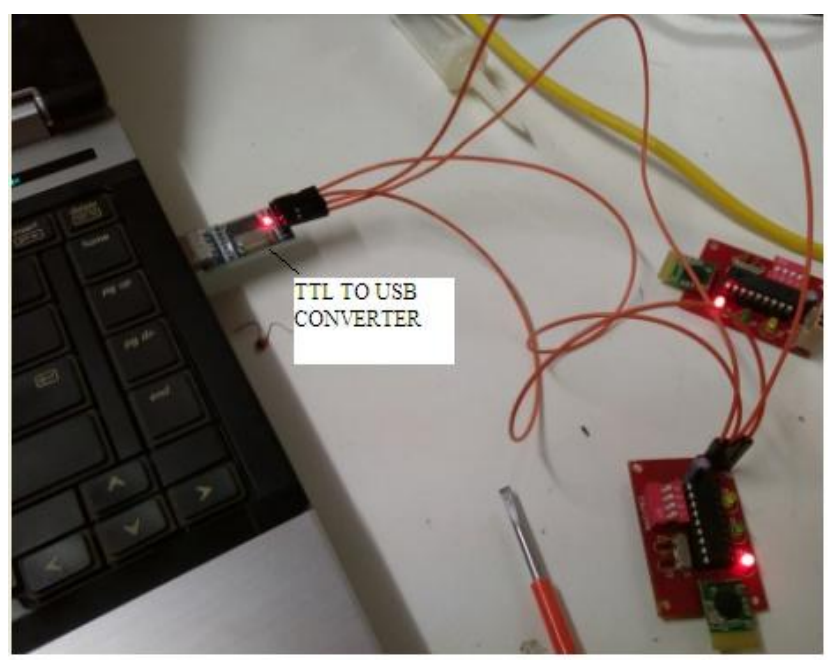

Fig-5: CC2500 receiver connected to laptop

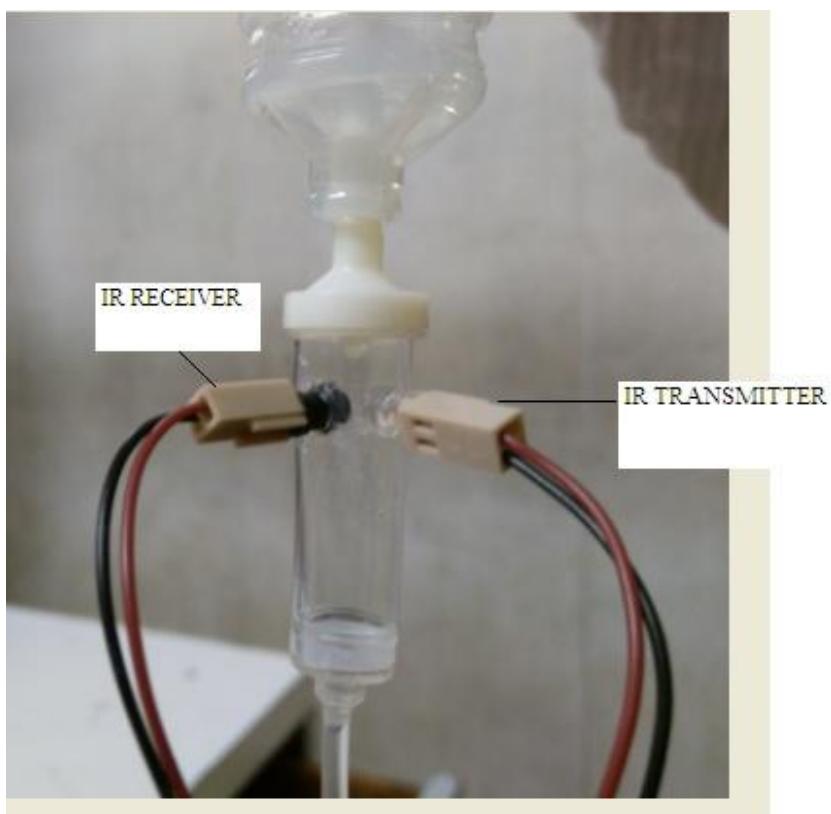

Fig-6: IR transreciever connected to saline bottle

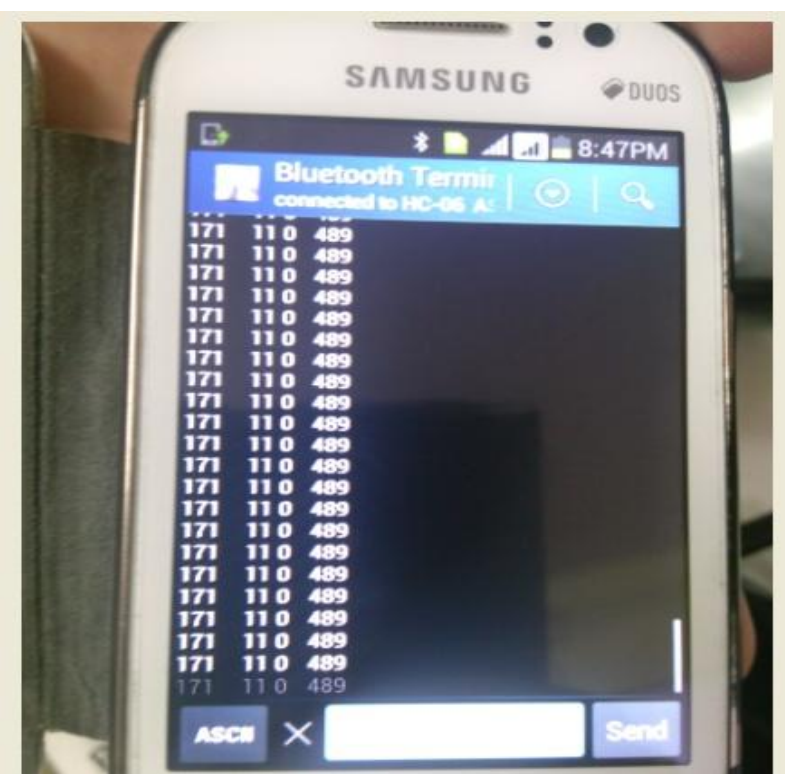

Fig-7: Bluetooth terminal application window

\section{CONCLUSION}

This paper proposes the system which can automatically monitor the saline flow rate by using microcontroller. It can wirelessly send the data to nurse's or doctor's computer and display the results in the form of saline droplet rate, number of droplets coming from saline bottle, saline solution given to the patient in $\mathrm{ml}$ and remaining time to empty the saline bottle with the help of serial port test software. The system is reliable, cost effective and convenient for nurses. It can be reused for the next saline bottle. It is beneficial for nurses as well as doctors at rural hospitals. Nurses can easily monitor the saline level from distance. It is mainly advantageous at night timing as there is no need for nurses to go to patient's bed to check the level of saline in the bottle.

\section{ACKNOWLEDGMENT}

The author M.G. Chidgopkar would like to acknowledge the support of Dr. S. D. Deshmukh, Principal, Jawaharlal Nehru Engineering College, Aurangabad, Maharashtra, and Prof. J.G. Rana, Head of theDepartment, electronics and telecommunication, Jawaharlal Nehru Engineering College, Aurangabad, Maharashtra, for their encouragement to the authors.

\section{REFERENCES}

[1]. Goepel, Ernst. "The ink drop sensor-a means of making ink-jet printers more reliable." CompEuro'89.,'VLSI and Computer Peripherals. VLSI and Microelectronic Applications in Intelligent Peripherals and their Interconnection Networks', Proceedings..IEEE, 1989.

[2]. Ishijima M [1993]. "Monitoring of Electro cardiograms in Bed without Utilizing Body Surface Electrodes", IEEE Transactions on Biomedical Engineering, , 40(6)

[3]. Nash, J. H., G. G. Leiter, and F. Grimm. "Sampling Device for Liquid Droplets." Review of Scientific Instruments 38.1 (2004): 73-77.

[4]. Peter Leijdekkers and Valerie Gay [2008]. "A self-test to detect a heart attack using a mobile phone and wearable sensors", Proceedings of the 21st IEEE International Symposium on Computer-Based Medical Systems , , 93-98

[5]. Zeng, H., and Y. Zhao. "Design and implementation of liquid droplet based motion sensing." Solid-State Sensors, Actuators and Microsystems Conference, 2009.TRANSDUCERS 2009.International.IEEE, 2009.

[6]. C.C. Gavimath, KrishnamurtyBhat, C. L. Chayalakshmi, R. S. Hooli, B. E. Ravishankera (2012) Design and Development Of Versatile Saline Flow rate Measurement System and GSM based remote monitoring device International Journal of Pharmaceutical Applications ISSN 0976-2639.Vol 3, Issue 1,pp 277-281 http://www.bipublication.com

[7]. Thongpance, Nuntachai, YuttanaPititeeraphab, and MatidaOphasphanichayakul. "The design and construction of infusion pump calibrator." Biomedical Engineering International Conference (BMEiCON), 2012.IEEE, 2012. 